\title{
microRNA-504 inhibits cancer cell proliferation via targeting CDK6 in hypopharyngeal squamous cell carcinoma
}

\author{
NAOKO KIKKAWA ${ }^{1,2^{*}}$, TAKASHI KINOSHITA ${ }^{1,2^{*}}$, NIJIRO NOHATA ${ }^{1,2}$, TOYOYUKI HANAZAWA ${ }^{2}$, \\ NORIKO YAMAMOTO ${ }^{1}$, ICHIRO FUKUMOTO ${ }^{1}$, TAKESHI CHIYOMARU ${ }^{3}$, HIDEKI ENOKIDA $^{3}$, \\ MASAYUKI NAKAGAWA ${ }^{3}$, YOSHITAKA OKAMOTO ${ }^{2}$ and NAOHIKO SEKI ${ }^{1}$ \\ Departments of ${ }^{1}$ Functional Genomics and ${ }^{2}$ Otorhinolaryngology/Head and Neck Surgery, \\ Chiba University Graduate School of Medicine, Chiba; ${ }^{3}$ Department of Urology, \\ Kagoshima University Graduate School of Medical and Dental Sciences, Kagoshima, Japan
}

Received January 7, 2014; Accepted February 28, 2014

DOI: $10.3892 /$ ijo.2014.2349

\begin{abstract}
Our recent study of the microRNA (miRNA) expression signature of hypopharyngeal squamous cell carcinoma (HSCC) revealed that microRNA-504 (miR-504) is significantly downregulated in HSCC tissues, suggesting that this miRNA is a candidate tumor suppressor. However, several previous reports indicated that $m i R-504$ has an oncogenic function through targeting TP53. The aim of this study was to investigate the functional significance of $m i R-504$ in cancer cells and to identify novel targets regulated by this miRNA in HSCC cells. First, we confirmed the downregulation of $m i R-504$ in HSCC clinical specimens $(\mathrm{P}<0.0001)$ by qPCR. Using two sources of $m i R-504$ to restore function, we observed significant inhibition of cancer cell proliferation in head and neck SCC (HNSCC) cell lines (FaDu, SAS and HSC3) and HCT116 colon carcinoma cells (p53 $3^{++}$and $\mathrm{p} 53^{-/-}$). In HNSCC cells, induction of cell cycle arrest was observed by $m i R-504$ transfection. To identify the molecular targets of $m i R-504$, we performed gene expression analysis of $m i R-504$ transfectants and in silico database analyses. Our data showed that cell cycle-related genes $(R B 1, C D K 6, C D C 23$ and $C C N D 1)$ were candidate target genes of $m i R-504$. In HSCC clinical specimens, the expression of cyclin-dependent kinase 6 (CDK6) was significantly higher in cancer tissues compared to noncancer tissues $(\mathrm{P}=0.0004)$. A significant inverse correlation between $C D K 6$ and $m i R-504$ expression was found ( $\mathrm{r}=-0.43$, $\mathrm{P}=0.0039$ ). Expression of $m i R-504$ inhibited $C D K 6$ expression in HNSCC cells. Loss of tumor-suppressive miR-504
\end{abstract}

Correspondence to: Dr Naohiko Seki, Department of Functional Genomics, Chiba University Graduate School of Medicine, 1-8-1 Inohana, Chuo-ku, Chiba 260-8670, Japan

E-mail: naoseki@faculty.chiba-u.jp

*Contributed equally

Key words: microRNA, miR-504, tumor suppressor, head and neck squamous cell carcinoma, cyclin-dependent kinase 6 enhanced HSCC cell proliferation through targeting CDK6. The identification of novel tumor-suppressive $m i R$-504-mediated molecular pathways and targets provide new insights into HSCC oncogenesis.

\section{Introduction}

Head and neck squamous cell carcinoma (HNSCC) is the sixth most common cancer in the world and approximately 500,000 cases are diagnosed every year (1). In spite of considerable advances in multimodality therapy, including surgery, radiotherapy and chemotherapy, the overall 5-year survival rate for patients with HNSCC is only approximately $50 \%$ (2). Hypopharyngeal SCC (HSCC) comprises $20 \%$ of all HNSCC, with an incidence of approximately 10 cases per million people-years (3). HSCC has a very poor prognosis compared with other HNSCC, with 5-year survival rates ranging from $30-35 \%(4,5)$. Local tumor recurrence and distant metastasis after conventional therapy appear to be major contributing factors for restricted survival of HSCC patients. Survival rates of HSCC patients have not markedly improved despite recent advanced combination therapies (6). Therefore, understanding the molecular pathways of metastasis accompanying HSCC would help to improve diagnosis, approaches to therapy and prevention of the disease.

The discovery of non-coding RNAs (ncRNAs) in the human genome was an important conceptual breakthrough in the post-genome sequencing era (7). Improved understanding of ncRNAs is necessary for continued progress in cancer research. microRNAs (miRNAs) are endogenous small ncRNA molecules (18-25 bases in length) that regulate protein-coding gene expression by repressing translation or cleaving RNA transcripts in a sequence-specific manner (8). Currently, 2,578 human mature miRNAs are registered at miRBase release 20.0 (http://www.mirbase.org/). miRNAs are unique in their ability to regulate multiple protein-coding genes. Bioinformatic predictions indicate that miRNAs regulate approximately $30-60 \%$ of the protein-coding genes in the human genome (9).

Numerous reports suggest that miRNAs are aberrantly expressed in many human cancers and that they play significant 
roles in the initiation, development, and metastasis of those cancers $(10,11)$. Some highly expressed miRNAs can function as oncogenes by repressing tumor suppressors, whereas low level miRNAs can function as tumor suppressors by negatively regulating oncogenes $(10,12)$. It is believed that normal regulatory mechanisms can be disrupted by the aberrant expression of tumor-suppressive or oncogenic miRNAs in cancer cells. Therefore, identification of aberrantly expressed miRNAs is an important first step toward elucidating miRNA-mediated oncogenic pathways.

Based on these considerations, we have constructed miRNA expression signatures using HNSCC clinical specimens and investigated the specific role of miRNAs in HNSCC oncogenesis using differentially expressed miRNAs $(13,14)$. Our recent studies demonstrated that $m i R-1, m i R-29 s, m i R-$ $133 a, m i R-218, m i R-489$ and $m i R-874$ functioned as tumor suppressors in HNSCC through their targeting of several types of oncogenic genes (13-23). Our HSCC and esophageal SCC miRNA expression signatures revealed that $m i R-504$ was significantly downregulated in cancer tissues, suggesting that this miRNA is a candidate tumor suppressor in human SCC cells $(13,24)$. However, several recent reports indicated that miR-504 functions as an oncogene $(25,26)$. These data contradict our hypothesis that $m i R-504$ functions as a tumor suppressor. The aim of this study was to investigate the functional significance of $m i R-504$ in cancer cells and to identify novel targets regulated by $m i R-504$ in HSCC cells.

We used two different sources of mature miR-504 to restore miR-504 function. Transfection of those miRNAs inhibited cancer cell proliferation. Genome-wide gene expression analysis of miR-504 transfectants and in silico database analysis showed that cyclin-dependent kinase 6 (CDK6) was a candidate target of $m i R-504$ in HSCC cells. Tumor suppressive $m i R$-504-regulated targets provide new insight into the potential mechanisms of HSCC oncogenesis and suggest novel therapeutic strategies for treatment of the disease.

\section{Materials and methods}

Clinical specimens. Twenty-three pairs of primary HSCC and corresponding normal epithelial samples were obtained from patients with HSCC at Chiba University Hospital (Chiba, Japan) from 2005 to 2013. The samples considered normal were free of cancer cells as determined by pathologic examination. The backgrounds and clinicopathological characteristics of the patient are summarized in Table I. The patients were classified according to the 2002 Union for International Cancer Control (UICC) TNM staging criteria prior to treatment. Written consent for tissue donation for research purposes was obtained from each patient before tissue collection. The protocol was approved by the Institutional Review Board of Chiba University. The specimens were immersed in RNAlater (Qiagen, Valencia, CA, USA) and stored at $-20^{\circ} \mathrm{C}$ until RNA was extracted.

RNA isolation. Total RNA was isolated using TRIzol reagent (Invitrogen, Carlsbad, CA, USA) according to the manufacturer's protocol. RNA concentrations were determined spectrophotometrically, and molecular integrity was checked by gel electrophoresis. RNA quality was confirmed using an
Agilent 2100 Bioanalyzer (Agilent Technologies, Santa Clara, CA, USA).

Cell culture. The following human cell lines were used: FaDu (derived from a primary lesion of hypopharyngeal SCC), SAS (derived from a primary lesion of tongue SCC), HSC3 (derived

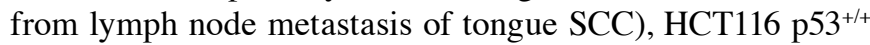
(derived from a colon adenocarcinoma) and its $\mathrm{p} 53^{-/-}$derivative. All cell lines were grown in Dulbecco's modified Eagle's medium (DMEM) supplemented with $10 \%$ fetal bovine serum in a humidified atmosphere containing $5 \% \mathrm{CO}_{2}$ at $37^{\circ} \mathrm{C}$.

Quantitative real-time RT-PCR ( $q P C R)$. cDNA synthesis and $\mathrm{PCR}$ procedures were described in our previous reports $(13,27)$. The expression levels of miR-504 (Assay ID: 002084) were analyzed by TaqMan quantitative real-time PCR (TaqMan ${ }^{\circledR}$ MicroRNA Assay; Applied Biosystems) and normalized to RNU48 (Assay ID: 001006). TaqMan ${ }^{\circledR}$ probes and primers for CDK6 (P/N: Hs01026371_m1), RB1 (P/N: Hs01078066_m1), CDC23 (P/N: 00946641_m1), CCND1 (P/N: 00765553_m1) and $G U S B$ (P/N: Hs00939627_m1) as an internal control were obtained from Applied Biosystems (Assay-On-Demand Gene Expression Products). The $\Delta \Delta \mathrm{Ct}$ method was adopted and applied to calculate the relative quantities of subject genes. All reactions were performed in triplicate and included negative control reactions that lacked cDNA.

Mature miRNA transfection. To perform gain of function studies, we utilized two different sources of mature miR-504: miR-504-A, Ambion Pre-miR miRNA Precursor, PM12429 (Applied Biosystems) and miR-504-T, miRIDIAN Mimic, MIMAT0002875 (Thermo Scientific Dharmacon, Waltham, MA, USA). Pre-miR Negative Control \#2 (AM17111, Applied Biosystems) was used for negative control experiments. The miRNA transfection procedures and confirmation of miRNA transfection efficiency were described in our previous reports $(13,27)$.

Cell proliferation assay. Cells were transfected with $10 \mathrm{nM}$ miRNA by reverse transfection and plated in 96-well plates at $3 \times 10^{3}$ cells per well. After $72 \mathrm{~h}$, cell proliferation was determined with the XTT assay using the Cell Proliferation Kit II (Roche Molecular Biochemicals, Mannheim, Germany) as previously reported $(13,27)$.

Flow cytometry. Cell cycle status was examined using an APC BrdU Flow kit (BD Bioscience, San Jose, CA, USA) according to the manufacturer's protocol. Briefly, SAS and FaDu cells were transiently transfected with miR-control, $m i R-504-\mathrm{A}$ or miR-504-T. Seventy-two hours after transfection, $10 \mu \mathrm{M}$ BrdU was added to the medium and incubated for $6 \mathrm{~h}$. The cells were then trypsinized and fixed with paraformaldehyde and permeabilized with saponin. After DNase treatment, the cells were stained with anti-BrdU antibodies and 7AAD and analyzed with a FACSCalibur flow cytometer (BD Bioscience).

Target gene search for $m i R-504$. To identify miR-504 target genes, we used genome-wide gene expression analysis and in silico analysis. First, we performed genome-wide gene expression analysis using miR-504 transfection of SAS and 
Table I. Patient characteristics.

\begin{tabular}{|c|c|c|c|c|c|c|}
\hline No. & Sex & $\mathrm{T}$ & $\mathrm{N}$ & M & Stage & Differentiation \\
\hline 1 & $\mathrm{M}$ & $4 a$ & 0 & 0 & IVA & Moderate \\
\hline 2 & M & 3 & 1 & 0 & III & Poor \\
\hline 3 & $\mathrm{M}$ & 2 & $2 c$ & 0 & IVA & Moderate \\
\hline 4 & M & 2 & $2 b$ & 0 & IVA & Poor \\
\hline 5 & $\mathrm{M}$ & 2 & $2 b$ & 0 & IVA & Poor \\
\hline 6 & $\mathrm{~F}$ & $4 a$ & 0 & 0 & IVA & Well \\
\hline 7 & $\mathrm{M}$ & 2 & $2 b$ & 0 & IVA & Moderate \\
\hline 8 & $\mathrm{M}$ & 2 & 0 & 0 & II & Moderate \\
\hline 9 & $\mathrm{M}$ & 3 & $2 b$ & 0 & IVA & Moderate \\
\hline 10 & $\mathrm{M}$ & $4 a$ & $2 b$ & 0 & IVA & Moderate \\
\hline 11 & M & 3 & $2 b$ & 0 & IVA & Poor \\
\hline 12 & $\mathrm{~F}$ & $4 \mathrm{a}$ & $2 \mathrm{c}$ & 0 & IVA & Poor \\
\hline 13 & M & $4 a$ & $2 c$ & 0 & IVA & Well \\
\hline 14 & $\mathrm{M}$ & $4 b$ & $2 c$ & 0 & IVB & Moderate \\
\hline 15 & M & $4 a$ & 1 & 0 & IVA & Well \\
\hline 16 & $\mathrm{~F}$ & $4 a$ & $2 \mathrm{c}$ & 0 & IVA & Moderate \\
\hline 17 & $\mathrm{M}$ & $4 \mathrm{a}$ & 1 & 1 & IVC & Moderate \\
\hline 18 & $\mathrm{M}$ & $4 \mathrm{a}$ & $2 \mathrm{c}$ & 0 & IVA & Poor \\
\hline 19 & $\mathrm{M}$ & 2 & 0 & 0 & II & Moderate \\
\hline 20 & $\mathrm{M}$ & $4 a$ & $2 c$ & 0 & IVA & Moderate \\
\hline 21 & $\mathrm{~F}$ & $4 \mathrm{a}$ & 1 & 0 & IVA & Poor \\
\hline 22 & $\mathrm{M}$ & $4 \mathrm{a}$ & $2 c$ & 0 & IVA & Well \\
\hline 23 & $\mathrm{M}$ & $4 a$ & 0 & 0 & IVA & Well \\
\hline
\end{tabular}

FaDu. SurePrint G3 Human GE 8x60K Microarray (Agilent Technologies) was used for expression profiling of $m i R-504$ transfectants in comparison with negative control miRNA transfectants. The genes that were downregulated in $m i R-504$ transfectant were then categorized into Kyoto Encyclopedia of Genes and Genomes (KEGG) pathways using GeneCodis analysis (28) (http:/genecodis.cnb.csic.es/). The target site for miR-504 was analyzed with TargetScan Release 6.2 (http:// www.targetscan.org/).

Western blotting. Cells were harvested $72 \mathrm{~h}$ after transfection and lysates were prepared. Protein $(50 \mu \mathrm{g})$ from each lysate was separated on a Mini-Protean TGX gel (Bio-Rad, Hercules, CA, USA) and transferred to PVDF membranes. Immunoblotting was performed with mouse $C D K 6$ antibody (1:500, \#3136, Cell Signaling Technology, Danvers, MA, USA) with GAPDH antibody (1:1,000, ab8245, Abcam, Cambridge, UK) used as an internal control. The membrane was washed and incubated with anti-mouse IgG HRP-linked antibody (\#7076, Cell Signaling Technology). Complexes were visualized with an Immun-Star ${ }^{\mathrm{TM}}$ Western Chemiluminescence kit (Bio-Rad), and the expression levels of these genes were evaluated by ImageJ software (ver.1.44; http://rsbweb.nih.gov/ij/).

Statistical analysis. The relationships between two groups and the numerical values obtained by qPCR were analysed using

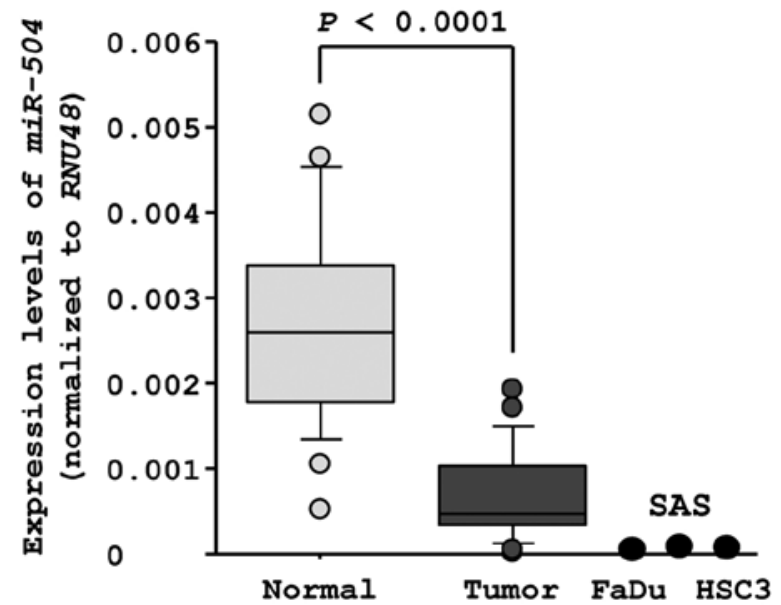

Figure 1. Expression levels of $m i R-504$ in HSCC clinical specimens and cell lines. Expression levels of $m i R-504$ in HSCC clinical specimens and cell lines were measured by qPCR. RNU48 was used for normalization.

the paired t-test. Spearman's rank test was used to evaluate the correlation between the expression of $m i R-504$ and target genes. The relationships among more than three variables and numerical values were analysed using the Bonferroni adjusted Mann-Whitney U test. All analyses were performed using Expert StatView (version 4, SAS Institute Inc., Cary, NC, USA).

\section{Results}

Expression of miR-504 in HSCC clinical specimens and cell lines. To validate our past miRNA profiling results, we evaluated $m i R-504$ expression in 23 clinical HSCC specimens. The expression levels of $m i R-504$ were significantly lower in tumor tissues than in corresponding adjacent normal epithelia ( $m i R-504$ expression normalized to RNU48: normal, $0.0026 \pm 0.0011$; tumor, $0.00070 \pm 0.00052, \mathrm{P}<0.0001$, Fig. 1). The expression levels of miR-504 in HNSCC cell lines were also lower than those in normal epithelia ( $m i R-504$ expression normalized to RNU48: FaDu, 0.000026; SAS, 0.00016; HSC3, 0.000025; Fig. 1).

Effects of miR-504 restoration on the proliferation of HNSCC cell lines. To investigate the role of $m i R-504$, we performed gain-of-function studies using mature miRNA transfection of three HNSCC cell lines (FaDu, SAS and HSC3). We utilized two sources of mature miR-504 (miR-504-A, Ambion; $m i R-504-\mathrm{T}$, Thermo Scientific Dharmacon) to ensure reproducibility of the data.

The XTT assay demonstrated that cell proliferation was significantly inhibited in miR-504 transfectants in comparison with the mock or miR-control transfectant cells. Specifically, we observed the following growth, expressed as a percentage of the mock: i) FaDu-mock, 100.0 \pm 1.0 ; miR control, 92.6 \pm 2.7 ; $m i R-504-\mathrm{A}, 45.5 \pm 2.3$; miR-504-T, 76.4 \pm 1.9 ; ii) SAS-mock,

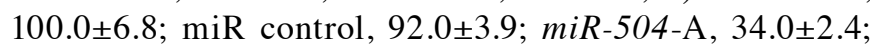
$m i R-504-\mathrm{T}, 45.1 \pm 3.3$; iii) HSC3-mock, 100.0 \pm 3.7 ; miR control,

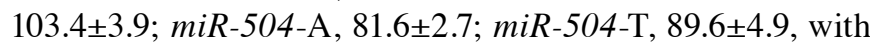
$\mathrm{P}<0.0083$ (Fig. 2). 

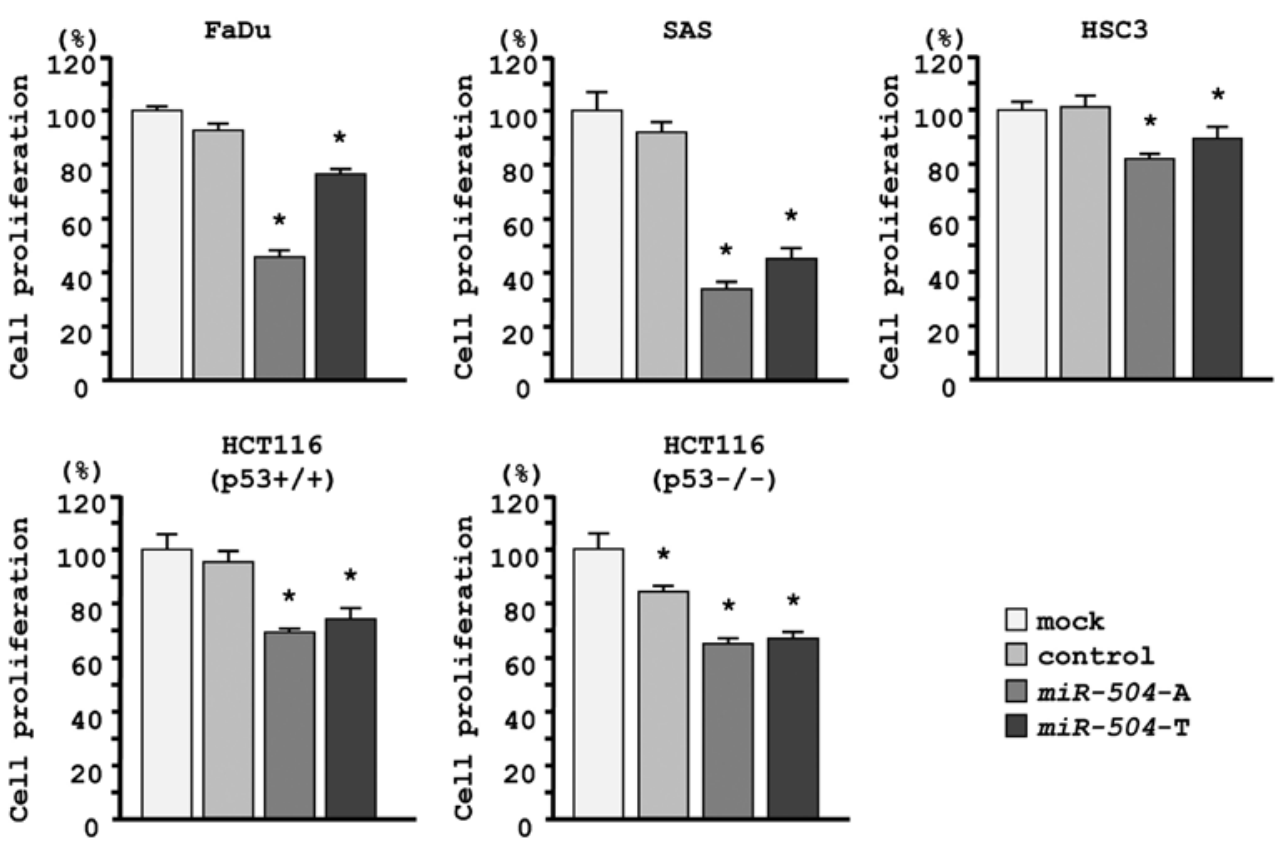

Figure 2. Effect of $m i R-504$ transfection on the proliferation of cancer cell lines. Cell proliferation $72 \mathrm{~h}$ after transfection with $m i R-504$ (10 $\mathrm{nM})$ was determined with the XTT assay. Two sources of mature miR-504 (miR-504-A, Ambion and miR-504-T, Thermo Scientific Dharmacon) were utilized to ensure reliability of the data. ${ }^{*} \mathrm{P}<0.0083$.

A

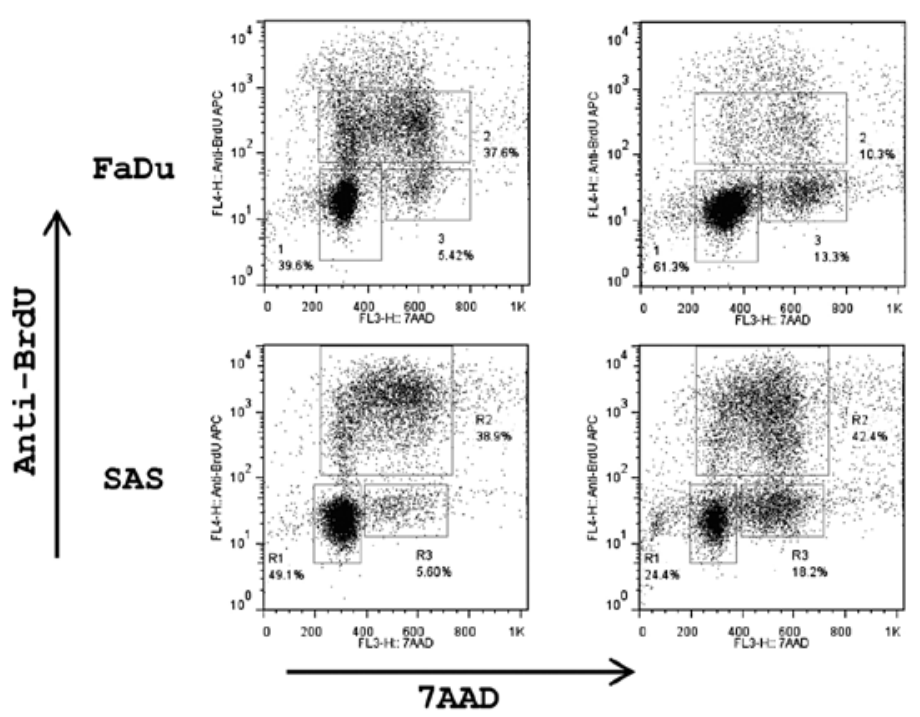

\section{$\operatorname{miR}-504-\mathrm{T}$}
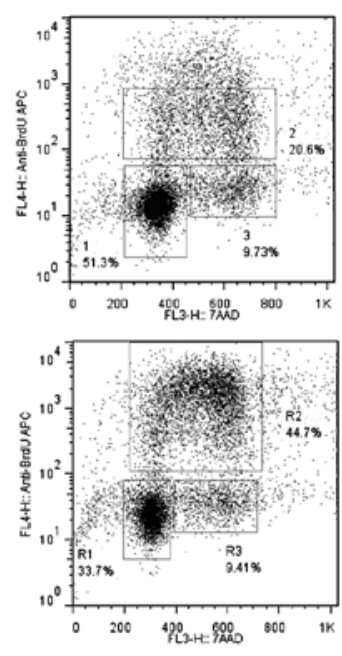

B

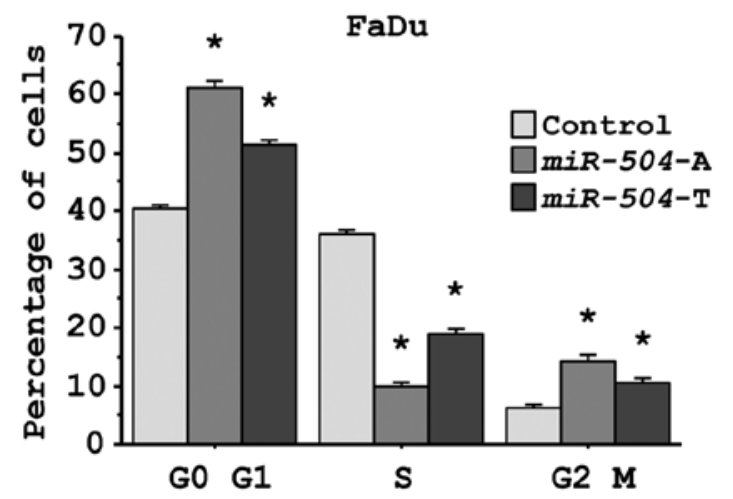

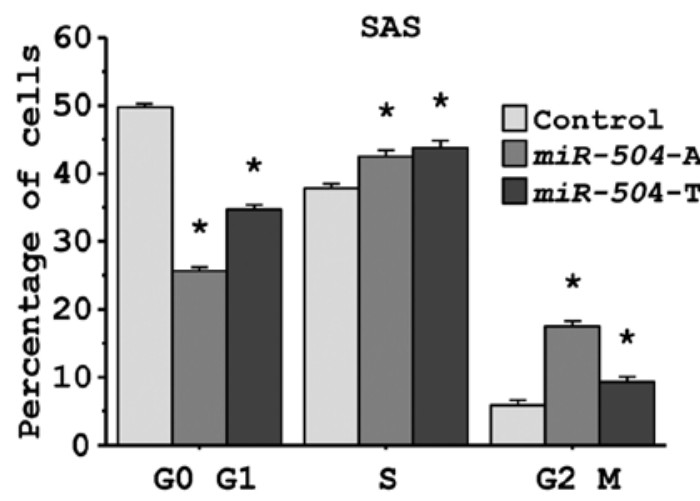

Figure 3. Effect of miR-504 transfection on cell cycle status of FaDu and SAS cell lines. (A) Typical cell cycle analyses of FaDu and SAS cell lines transfected with miR control, miR-504-A and miR-504-T. Flow cytometric analysis of cells stained with anti-BrdU and 7AAD allowed the discrimination of population subsets that resided in G0/G1 (lower left gate), S (top gate) or G2/M (lower right gate) phases of the cell cycle. (B) The bar chart represents the percentages of cells in the G0/G1, S or G2/M phases of the cell cycle. "P<0.0167. 
Table II. Significantly enriched annotations among downregulated genes by miR-504 transfection in FaDu.

\begin{tabular}{lll}
\hline $\begin{array}{l}\text { No. of } \\
\text { genes }\end{array}$ & P-value & \multicolumn{1}{c}{ Annotations } \\
\hline 19 & & \\
15 & $1.28 \mathrm{E}-06$ & Cell cycle \\
14 & $1.70 \mathrm{E}-08$ & Ribosome biogenesis in eukaryotes \\
14 & $1.49 \mathrm{E}-07$ & Systemic lupus erythematosus \\
13 & $2.78 \mathrm{E}-05$ & Spliceosome \\
12 & $1.44 \mathrm{E}-03$ & Purine metabolism \\
11 & $7.99 \mathrm{E}-05$ & Pyrimidine metabolism \\
11 & $1.37 \mathrm{E}-03$ & Ubiquitin mediated proteolysis \\
9 & $3.74 \mathrm{E}-03$ & Oocyte meiosis \\
9 & $9.33 \mathrm{E}-03$ & Measles \\
8 & $3.69 \mathrm{E}-03$ & Progesterone-mediated oocyte maturation \\
7 & $3.93 \mathrm{E}-04$ & Nucleotide excision repair \\
7 & $3.56 \mathrm{E}-03$ & p53 signaling pathway \\
7 & $5.44 \mathrm{E}-03$ & Chronic myeloid leukemia \\
6 & $3.58 \mathrm{E}-04$ & RNA polymerase \\
6 & $1.22 \mathrm{E}-03$ & DNA replication \\
6 & $1.83 \mathrm{E}-03$ & Aminoacyl-tRNA biosynthesis \\
6 & $4.62 \mathrm{E}-03$ & Mineral absorption \\
6 & $5.72 \mathrm{E}-03$ & Arginine and proline metabolism \\
5 & $1.38 \mathrm{E}-03$ & Mismatch repair \\
5 & $1.83 \mathrm{E}-03$ & Homologous recombination \\
5 & $3.46 \mathrm{E}-03$ & Citrate cycle (TCA cycle) \\
4 & $3.96 \mathrm{E}-03$ & One carbon pool by folate \\
3 & $6.43 \mathrm{E}-03$ & Valine, leucine and isoleucine biosynthesis \\
\hline & & \\
\hline
\end{tabular}

Because $m i R-504$ has been reported to promote tumorigenicity by regulating TP53, we evaluated functional effects of $m i R-504$ in HCT116 p53 $3^{+/+}$cells and its p53/- derivative cell line. The XTT assay showed that cell proliferation was significantly inhibited by $m i R-504$ transfection in both cell lines, suggesting that $m i R-504$ functioned as a tumor suppressor regardless of p53 status. We observed the following growth, expressed as a percentage of the mock: i) HCT116 $553^{+/+}$-mock, $100.0 \pm 3.7$; miR control, 94.5 $\pm 3.8 ;$ miR-504-A, 68.7 \pm 2.2 ; $m i R-504-\mathrm{T}, 74.9 \pm 3.8$; ii) HCT116 p53 ${ }^{-/-}$-mock, $100.0 \pm 4.4$; miR

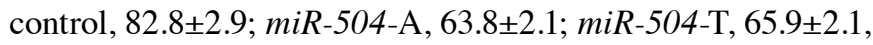
with $\mathrm{P}<0.0083$ (Fig. 2).

Effects of miR-504 restoration on cell cycle status in HNSCC cell lines. To study whether miR-504 affected the cell cycle status of cancer cells, we performed flow cytometric analysis of cells stained with anti-BrdU and 7AAD allowing the discrimination of cell fractions that resided in $\mathrm{G} 0 / \mathrm{G} 1, \mathrm{~S}$ or G2/M phases of the cell cycle (Fig. 3A). The fraction of FaDu cells in the G0/G1 phase was significantly larger in $m i R-504$ transfectants in comparison with the miR control transfectants, whereas the fraction of SAS cells in G2/M phase was significantly larger in miR-504 transfectants (Fig. 3B).
Table III. Significantly enriched annotations among downregulated genes by $m i R-504$ transfection in SAS.

\begin{tabular}{|c|c|c|}
\hline $\begin{array}{l}\text { No. of } \\
\text { genes }\end{array}$ & P-value & Annotations \\
\hline 24 & $9.36 \mathrm{E}-04$ & Pathways in cancer \\
\hline 21 & $2.54 \mathrm{E}-06$ & $\begin{array}{l}\text { Protein processing in endoplasmic } \\
\text { reticulum }\end{array}$ \\
\hline 20 & $8.23 \mathrm{E}-05$ & Focal adhesion \\
\hline 18 & $2.10 \mathrm{E}-06$ & Lysosome \\
\hline 17 & $7.50 \mathrm{E}-04$ & Huntington's disease \\
\hline 15 & $1.36 \mathrm{E}-04$ & Cell cycle \\
\hline 15 & $1.93 \mathrm{E}-03$ & Alzheimer's disease \\
\hline 15 & $6.78 \mathrm{E}-03$ & Endocytosis \\
\hline 14 & $6.72 \mathrm{E}-03$ & Tuberculosis \\
\hline 13 & $5.94 \mathrm{E}-05$ & Small cell lung cancer \\
\hline 13 & $2.17 \mathrm{E}-03$ & Oxidative phosphorylation \\
\hline 12 & $4.03 \mathrm{E}-05$ & p53 signaling pathway \\
\hline 12 & $2.00 \mathrm{E}-03$ & Oocyte meiosis \\
\hline 12 & $6.67 \mathrm{E}-03$ & Ubiquitin mediated proteolysis \\
\hline 10 & $9.11 \mathrm{E}-04$ & Melanoma \\
\hline 10 & $3.60 \mathrm{E}-03$ & Prostate cancer \\
\hline 9 & $3.55 \mathrm{E}-04$ & Lysine degradation \\
\hline 9 & $3.65 \mathrm{E}-03$ & Chronic myeloid leukemia \\
\hline 8 & $2.30 \mathrm{E}-03$ & Non-small cell lung cancer \\
\hline 8 & $5.70 \mathrm{E}-03$ & Glioma \\
\hline 8 & $9.15 \mathrm{E}-03$ & Pancreatic cancer \\
\hline 7 & $6.46 \mathrm{E}-03$ & Mineral absorption \\
\hline 6 & $2.91 \mathrm{E}-03$ & Citrate cycle (TCA cycle) \\
\hline 5 & $5.46 \mathrm{E}-03$ & Protein export \\
\hline
\end{tabular}

Identification of candidate target genes regulated by miR-504 in HNSCC cells. To identify miR-504 target genes, we used genome-wide gene expression analysis and in silico analysis. First, we performed genome-wide gene expression analysis using two cancer cell lines (FaDu and SAS) and selected genes downregulated by $m i R-504$ transfection compared with miR control transfection. In this analysis, 810 genes and 1,145 genes were recognized as downregulated genes $\left(\log _{2}\right.$ ratio <-0.5) in $\mathrm{FaDu}$ and SAS, respectively. Entries from the microarray data were approved by the Gene Expression Omnibus (GEO) and were assigned GEO accession no. GSE37119.

Next, genes downregulated in $m i R$-504-transfectants were categorized into KEGG pathways using GeneCodis analysis and 24 pathways were identified as significantly enriched in both lines (Tables II and III). Among these pathways, we focused on the 'cell cycle' pathway because this pathway has been implicated in cancer cell proliferation. A total of 19 genes were identified in this pathway and four genes $(R B 1$, $C D K 6, C D C 23$ and $C C N D 1$ ) had putative miR-504 target sites predicted by the TargetScan database (Table IV).

CDK6 is a candidate of miR-504 regulation in HNSCC cells. We investigated the expression levels of four candidate genes 
Table IV. Candidate target genes of miR-504 in the cell cycle pathway.

\begin{tabular}{|c|c|c|c|c|}
\hline \multirow[b]{2}{*}{ Gene } & \multicolumn{3}{|c|}{$\begin{array}{c}\log _{2} \text { ratio } \\
(m i R-504 / \mathrm{miR} \text {-control) }\end{array}$} & \multirow[b]{2}{*}{ miR-504 target site } \\
\hline & $\mathrm{FaDu}$ & SAS & Average & \\
\hline ANAPC10 & -1.40 & -1.49 & -1.44 & 0 \\
\hline$P C N A$ & -0.97 & -1.26 & -1.12 & 0 \\
\hline$R B 1$ & -0.55 & -1.37 & -0.96 & 1 \\
\hline$C C N D 2$ & -0.84 & -1.04 & -0.94 & 0 \\
\hline ANAPC11 & -0.66 & -1.17 & -0.91 & 0 \\
\hline CDK6 & -0.61 & -0.94 & -0.77 & 1 \\
\hline$A N A P C 5$ & -0.51 & -0.93 & -0.72 & 0 \\
\hline$C D K N 2 D$ & -0.02 & -1.26 & -0.64 & 0 \\
\hline$C D K 4$ & -0.75 & -0.52 & -0.63 & 0 \\
\hline CCNE1 & -0.53 & -0.56 & -0.54 & 0 \\
\hline$H D A C 1$ & -0.25 & -0.72 & -0.49 & 0 \\
\hline$A N A P C 4$ & -0.15 & -0.70 & -0.43 & 0 \\
\hline $\mathrm{CCNH}$ & -0.72 & -0.06 & -0.39 & 0 \\
\hline$C D C 23$ & -0.56 & -0.22 & -0.39 & 1 \\
\hline$C C N D 1$ & -0.14 & -0.63 & -0.39 & 1 \\
\hline$E 2 F 3$ & -0.41 & -0.11 & -0.26 & 0 \\
\hline$B U B 1$ & -0.54 & 0.06 & -0.24 & 0 \\
\hline$M A D 2 L 1$ & -0.63 & 0.20 & -0.22 & 0 \\
\hline CCNE2 & 0.28 & -0.50 & -0.11 & 0 \\
\hline
\end{tabular}

in HSCC clinical specimens. $C D K 6$ was significantly upregulated in cancer tissues $(\mathrm{P}=0.0004$, Fig. 4A). Furthermore, the expression of $C D K 6$ was inversely correlated with that of $m i R-504$ in HSCC specimens ( $\mathrm{r}=-0.43, \mathrm{P}=0.0039$, Fig. 4B).
We performed qPCR and western blotting in $\mathrm{FaDu}$ and SAS to investigate whether $C D K 6$ expression was downregulated by restoration of $m i R-504$. CDK6 mRNA expression was significantly repressed by $m i R-504$ transfection of FaDu cells, while no changes were observed in SAS cells (Fig. 5A). The expression levels of CDK6 protein were repressed in $m i R-504$ transfectants in comparison with mock or miR-control transfectants in both FaDu and SAS cells (Fig. 5B).

\section{Discussion}

Aberrant expression of miRNAs can disrupt the tightly regulated system by which miRNA regulates protein-coding RNA networks in cancer cells $(10,12)$. Therefore, studies of differentially expressed miRNAs in cancer cells provide important information regarding the molecular mechanisms underlying oncogenesis and metastasis. To elucidate the molecular mechanisms underlying HNSCC, we have identified tumorsuppressive miRNAs, focusing on their regulated molecular targets and novel cancer pathways based on HNSCC expression signatures $(13-24,27)$.

Our recent studies of miRNA expression signatures of HSCC and esophageal SCC showed that miR-504 was significantly reduced in cancer tissues compared to normal tissues $(13,24)$. Those results suggested that $m i R-504$ was a candidate tumor suppressor. In glioblastoma, $m i R-504$ expression was reported to be downregulated and functioned as a tumor suppressor by regulating mesenchymal genes (29). This finding is consistent with our results. However, $m i R-504$ has also been reported to have oncogenic functions. For example, a recent study showed that $m i R-504$ was a negative regulator of human TP53 and directly bound to its 3'-UTR region (25). Overexpression of miR-504 induced TP53 silencing and caused inhibition of p53-mediated apoptosis and cell cycle arrest in response to stress (25). Another report showed that
A

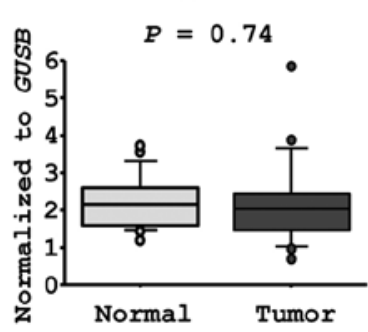

B

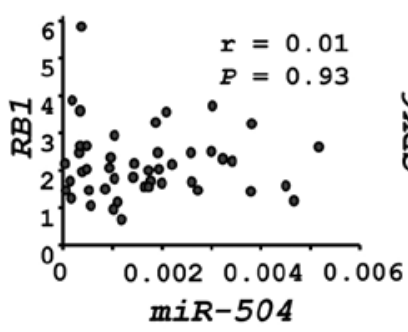

CDK6

$P=0.0004$
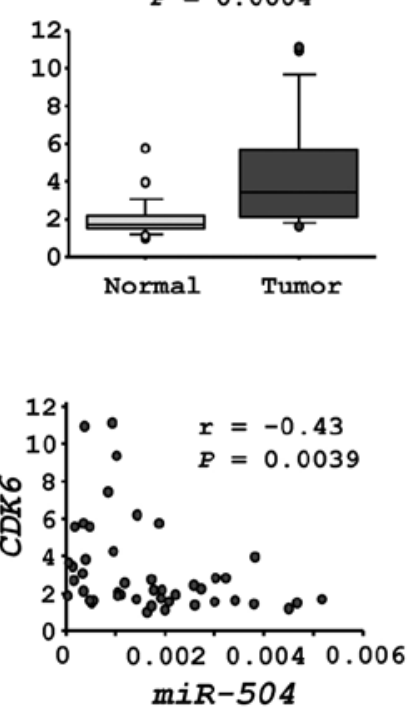

$C D C 23$

$P=0.57$
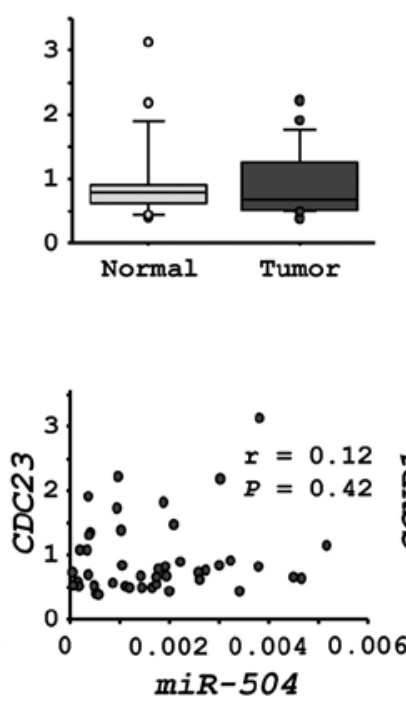

CCND1
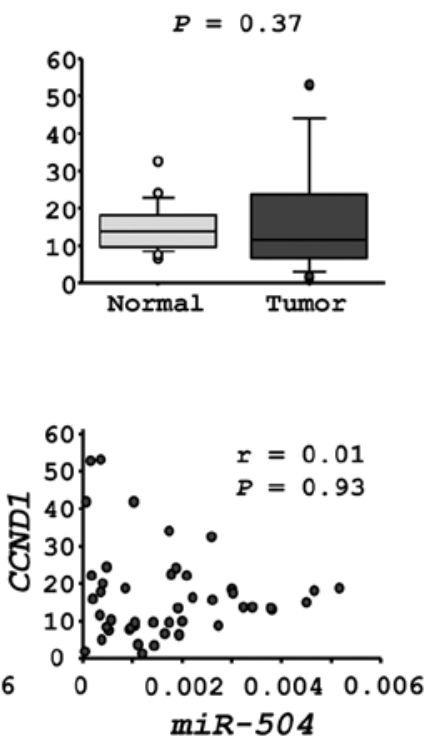

Figure 4. Expression levels of candidate target genes of $m i R-504$ in HSCC clinical specimens. (A) Expression levels of $m i R-504$ candidate target genes (RB1, $C D K 6, C D C 23$ and $C C N D 1$ ) in HSCC clinical specimens and adjacent normal epithelia were measured by qPCR. GUSB was used for normalization. (B) The expression levels of $m i R-504$ and the candidate genes in HSCC clinical specimens were plotted in scatter diagrams. Spearman's rank test was used to evaluate the correlation between the expressions of $m i R-504$ and the target genes. 
A

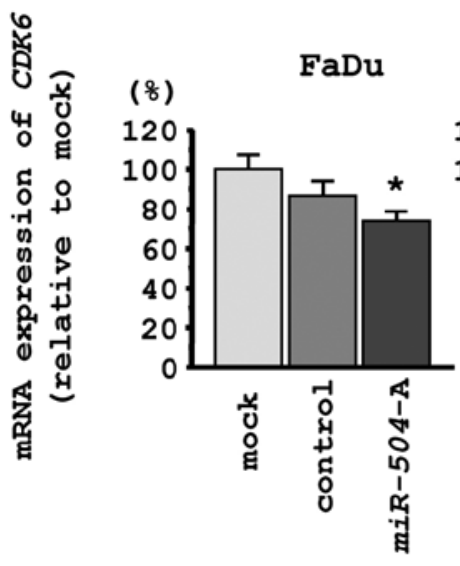

B

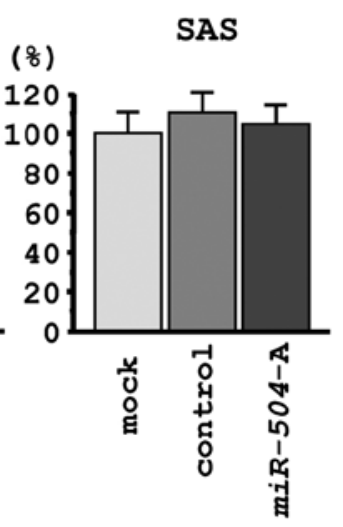

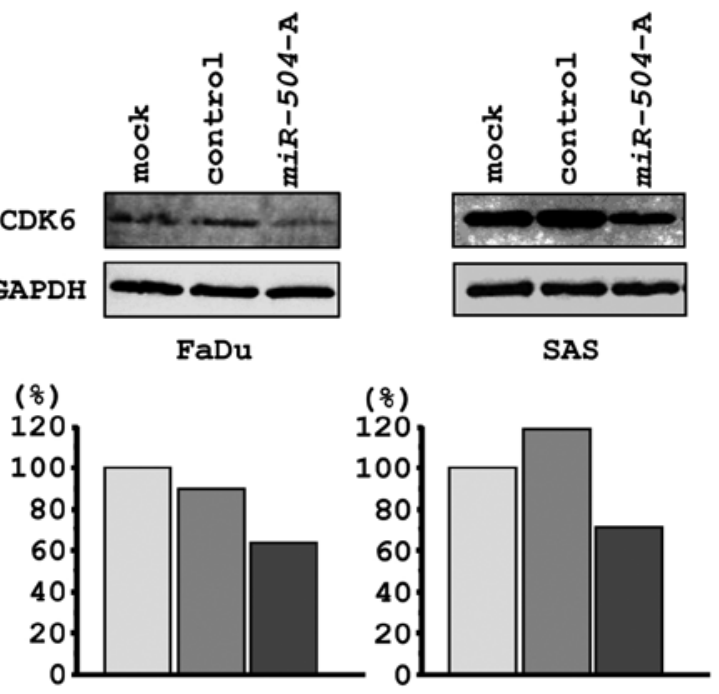

Figure 5. Regulation of CDK6 by miR-504. (A) The mRNA expression levels of CDK6 $72 \mathrm{~h}$ after transfection with mock, miR control or $m i R-504-\mathrm{A}$ in FaDu and SAS cell lines were determined by qPCR. GUSB was used for normalization. "P<0.0167. (B) The protein expression levels of CDK6 $72 \mathrm{~h}$ after transfection with mock, miR control or miR-504-A in FaDu and SAS were determined by western blotting. GAPDH was used for normalization.

ectopic expression of $m i R-504$ increased migration and invasion in an oral cancer cell line by targeting $F O X P 1$, a member of forkhead transcriptional factors (26).

We conducted two analyses to test the conclusions of the above reports. First, we restored function using two different sources of mature miR-504 in several cancer cell lines. In HNSCC cell lines, restoration of both types of miR-504 significantly inhibited cancer cell proliferation. Similar results were observed in HPV16- and HPV18-positive cervical-SCC cell lines (data not shown). Furthermore, we investigated the anti-proliferative effects of $m i R-504$ and p53 status using HCT116 $\mathrm{p}^{2} 3^{+/+}$and HCT116 $\mathrm{p} 53^{-/-}$cells. Our data demonstrated that the anti-proliferative effect was not affected by the p53 status. In this study, our data indicated that $m i R-504$ had a tumor-suppressive function, particularly promotion of cell cycle arrest.

A unique aspect of miRNAs is that one miRNA regulates many protein-coding genes. Thus, it is important to elucidate the molecular targets and pathways regulated by a single tumor suppressive molecule, miR-504, in cancer cells. To solve this problem, we performed genome-wide gene expression analysis using miR-504-transfectants. We categorized differentially expressed genes of $m i R$-504-transfectants into KEGG pathways. Several pathways were enriched in this analysis and we focused on 'cell cycle' pathways because miR-504-transfectants underwent cell cycle arrest. Finally, $C D K 6$ was chosen as a miR-504 target oncogenic gene that met several conditions. These included the following: i) mRNA sequence contained a putative $m i R-504$ binding site, ii) inhibition of its expression in $m i R-504$ transfects, and iii) overexpression in HSCC clinical specimens.

It is well known that CDK-cyclin complexes are deregulated in cancer cells, resulting in either continued proliferation or unscheduled re-entry into the cell cycle (30). Several CDK4/ $C D K 6$ inhibitors have been shown to induce G1 arrest and inhibit proliferation of tumor cells $(31,32)$. Our data indicated that restoration of $m i R-504$ repressed CDK6 and induced
$\mathrm{G} 1$ arrest in FaDu cell. On the other hand, in SAS cells, restoration of $m i R-504$ induced $\mathrm{G} 2$ arrest. We have no reasonable data to explain this phenomenon but it is possible that some G2 phase related genes were affected by $m i R-504$ in SAS cells. Thus, further study is needed.

In conclusion, downregulation of $m i R-504$ was frequently observed in HSCC clinical specimens. Restoration of miRNA significantly inhibited cancer cell proliferation, suggesting that miR-504 functioned as a tumor suppressor in HSCC cells. To the best of our knowledge, this is the first report demonstrating that tumor-suppressive miR-504 regulated 'cell cycle' pathways and that $C D K 6$ was a putative target. The identification of target oncogenes regulated by $m i R-504$ might lead to a better understanding of HSCC oncogenesis and the development of new therapeutic strategies to treat this disease.

\section{Acknowledgements}

This study was supported by JSPS KAKENHI Grant nos. 23592505, 24592590, 25462676 and 25861528.

\section{References}

1. Jemal A, Siegel R, Xu J and Ward E: Cancer statistics, 2010. CA Cancer J Clin 60: 277-300, 2010.

2. Leemans CR, Braakhuis BJ and Brakenhoff RH: The molecular biology of head and neck cancer. Nat Rev Cancer 11: 9-22, 2011.

3. Davies L and Welch HG: Epidemiology of head and neck cancer in the United States. Otolaryngol Head Neck Surg 135: 451-457, 2006.

4. Hoffman HT, Karnell LH, Shah JP, et al: Hypopharyngeal cancer patient care evaluation. Laryngoscope 107: 1005-1017, 1997.

5. Bova R, Goh R, Poulson M and Coman WB: Total pharyngolaryngectomy for squamous cell carcinoma of the hypopharynx: a review. Laryngoscope 115: 864-869, 2005.

6. Godballe C, Jorgensen $\mathrm{K}$, Hansen $\mathrm{O}$ and Bastholt L: Hypopharyngeal cancer: results of treatment based on radiation therapy and salvage surgery. Laryngoscope 112: 834-838, 2002.

7. Carthew RW and Sontheimer EJ: Origins and mechanisms of miRNAs and siRNAs. Cell 136: 642-655, 2009. 
8. Bartel DP: MicroRNAs: genomics, biogenesis, mechanism, and function. Cell 116: 281-297, 2004.

9. Filipowicz W, Bhattacharyya SN and Sonenberg N: Mechanisms of post-transcriptional regulation by microRNAs: are the answers in sight? Nat Rev Genet 9: 102-114, 2008

10. Esquela-Kerscher A and Slack FJ: Oncomirs - microRNAs with a role in cancer. Nat Rev Cancer 6: 259-269, 2006.

11. Tran N, O'Brien CJ, Clark J and Rose B: Potential role of microRNAs in head and neck tumorigenesis. Head Neck 32: 1099-1111, 2010.

12. Caldas $\mathrm{C}$ and Brenton JD: Sizing up miRNAs as cancer genes. Nat Med 11: 712-714, 2005.

13. Kikkawa N, Hanazawa T, Fujimura L, et al: miR-489 is a tumour-suppressive miRNA target PTPN11 in hypopharyngeal squamous cell carcinoma (HSCC). Br J Cancer 103: 877-84, 2010.

14. Nohata N, Hanazawa T, Kikkawa N, et al: Tumour suppressive microRNA-874 regulates novel cancer networks in maxillary sinus squamous cell carcinoma. Br J Cancer 105: 833-841, 2011.

15. Kinoshita T, Hanazawa T, Nohata N, et al: Tumor suppressive microRNA-218 inhibits cancer cell migration and invasion through targeting laminin-332 in head and neck squamous cell carcinoma. Oncotarget 3: 1386-1400, 2012.

16. Kinoshita T, Nohata N, Fuse M, et al: Tumor suppressive microRNA-133a regulates novel targets: moesin contributes to cancer cell proliferation and invasion in head and neck squamous cell carcinoma. Biochem Biophys Res Commun 418: 378-383, 2012.

17. Kinoshita $\mathrm{T}$, Nohata $\mathrm{N}$, Watanabe-Takano H, et al: Actin-related protein $2 / 3$ complex subunit 5 (ARPC5) contributes to cell migration and invasion and is directly regulated by tumorsuppressive microRNA-133a in head and neck squamous cell carcinoma. Int J Oncol 40: 1770-1778, 2012.

18. Kinoshita T, Nohata N, Yoshino H, et al: Tumor suppressive microRNA-375 regulates lactate dehydrogenase B in maxillary sinus squamous cell carcinoma. Int J Oncol 40: 185-193, 2012.

19. Mutallip M, Nohata N, Hanazawa T, et al: Glutathione S-transferase P1 (GSTP1) suppresses cell apoptosis and its regulation by miR-133alpha in head and neck squamous cell carcinoma (HNSCC). Int J Mol Med 27: 345-352, 2011.

20. Nohata N, Hanazawa T, Kikkawa N, et al: Caveolin-1 mediates tumor cell migration and invasion and its regulation by miR-133a in head and neck squamous cell carcinoma. Int J Oncol 38: 209-217, 2011.
21. Nohata N, Hanazawa T, Kikkawa N, et al: Identification of novel molecular targets regulated by tumor suppressive miR-1/ miR-133a in maxillary sinus squamous cell carcinoma. Int $\mathbf{J}$ Oncol 39: 1099-1107, 2011.

22. Nohata N, Hanazawa T, Kinoshita T, et al: Tumour-suppressive microRNA-874 contributes to cell proliferation through targeting of histone deacetylase 1 in head and neck squamous cell carcinoma. Br J Cancer 108: 1648-1658, 2013.

23. Nohata N, Sone Y, Hanazawa T, et al: miR-1 as a tumor suppressive microRNA targeting TAGLN2 in head and neck squamous cell carcinoma. Oncotarget 2: 29-42, 2011.

24. Kano M, Seki N, Kikkawa N, et al: miR-145, miR-133a and miR-133b: tumor-suppressive miRNAs target FSCN1 in esophageal squamous cell carcinoma. Int J Cancer 127: 2804-2814, 2010.

25. Hu W, Chan CS, Wu R, et al: Negative regulation of tumor suppressor p53 by microRNA miR-504. Mol Cell 38: 689-699, 2010.

26. Yang $\mathrm{MH}$, Lin $\mathrm{BR}$, Chang $\mathrm{CH}$, et al: Connective tissue growth factor modulates oral squamous cell carcinoma invasion by activating a miR-504/FOXP1 signalling. Oncogene 31: 2401-2411, 2012 .

27. Ichimi T, Enokida H, Okuno Y, et al: Identification of novel microRNA targets based on microRNA signatures in bladder cancer. Int J Cancer 125: 345-352, 2009.

28. Tabas-Madrid D, Nogales-Cadenas R and Pascual-Montano A: GeneCodis3: a non-redundant and modular enrichment analysis tool for functional genomics. Nucleic Acids Res 40: W478-W483, 2012.

29. Ma X, Yoshimoto K, Guan Y, et al: Associations between microRNA expression and mesenchymal marker gene expression in glioblastoma. Neuro Oncol 14: 1153-1162, 2012.

30. Malumbres $\mathrm{M}$ and Barbacid $\mathrm{M}$ : Cell cycle, CDKs and cancer: a changing paradigm. Nat Rev Cancer 9: 153-166, 2009.

31. Musgrove EA, Caldon CE, Barraclough J, Stone A and Sutherland RL: Cyclin D as a therapeutic target in cancer. Nat Rev Cancer 11: 558-572, 2011.

32. Shapiro GI: Cyclin-dependent kinase pathways as targets for cancer treatment. J Clin Oncol 24: 1770-1783, 2006. 